\title{
Formation of PEO Coatings Modified by SiC Nanoparticles on the MA8 Magnesium Alloy
}

\author{
Dmitry V. Mashtalyar ${ }^{1}{ }^{*}$, Igor $M$. Imshinetskiy ${ }^{1}$, Konstantine $V$. Nadaraia ${ }^{1}$, Marina $V$. \\ Sidorova $^{1}$, Sergey L. Sinebryukhov ${ }^{1}$, and Sergey $V$. Gnedenkov ${ }^{1}$ \\ ${ }^{1}$ Institute of Chemistry of FEB RAS, 159 pr. 100-letiya Vladivostoka, Vladivostok, 690022, Russia
}

\begin{abstract}
The properties of coatings formed on the MA8 magnesium alloy by the plasma electrolytic oxidation in electrolytes containing silicon carbide nanoparticles in concentrations of 2,4 and $6 \mathrm{~g} / \mathrm{l}$ have been investigated. It has been shown that coatings, which contain nanoparticles, have a significant advantage in microhardenss and adhesive strength in comparison with the surface layers obtained without their use.
\end{abstract}

\section{Introduction}

Recently, magnesium alloys inspire a high interest due to such physical-mechanical properties of these materials as low density $\left(1.35-1.85 \mathrm{~g} \mathrm{~cm}^{-3}\right)$; high specific strength, stiffness, thermal conductivity and heat capacity; the ability to absorb the impact energy and reduce vibration. The main limiting factor of their wider usage is the high corrosion activity and low wear resistance. Note that major disadvantages of magnesium alloys can be eliminated by plasma electrolytic oxidation (PEO). This method allows obtaining protective coatings on different metals and alloys without thorough surface preparation before forming corrosion protective, wearproof PEO-layers with high adhesion to the substrate [1-3].

One of the directions of PEO's development involves the use of nanoscale materials that have certain physicochemical properties in the electrolyte. These properties allows improving the performance characteristics of the surface layers and expand the area of practical usage of coated samples [4-8].

In this work, the features of the formation and properties of coatings obtained by PEO method in silicate-fluoride electrolytes containing silicon carbide $(\mathrm{SiC})$ nanoparticles were studied. Advantages of silicon carbide have been proved in various industrial areas due to its high hardness, durability and chemical resistivity. It is actively used for formation abrasive materials, composites, and cutting equipment $[9,10]$.

This paper is devoted to the study of the mechanical properties of PEO layers formed on the MA8 magnesium alloy in silicate-fluoride electrolyte with the addition of $\mathrm{SiC}$ nanoparticles.

\footnotetext{
*Corresponding author: madiva@inbox.ru
} 


\section{Experiment}

Rectangular plates of a size of $15 \mathrm{~mm} \times 20 \mathrm{~mm} \times 2 \mathrm{~mm}$ made of the MA8 magnesium alloy (1.5 wt. \% Mn; 0.15 wt. \% Ce; Mg balance) were used as samples. For the aim of the alloy surface standardization the samples have been polished with sanding paper of different grain size $(600,800$, and 1200), washed with distilled water and alcohol.

The SiC nanopowder (CAS 409-21-2) with the particle size of $100 \mathrm{~nm}$ produced by the Sigma Aldrich (China) was used to produce the composite coating. Since at the plasma electrolytic oxidation the coating growth on the sample proceeds, as a rule, during anodic polarization, to ensure the maximal incorporation of particles into the coating, an anionic surfactant (sodium dodecylsulfate) was used as a stabilizer of the dispersed system. Its concentration in the final electrolyte was equal to $0.5 \mathrm{~g} / \mathrm{l}$, concentration of $\mathrm{SiC}$ nanoparticles was equal to $0,2,4$ and $6 \mathrm{~g} / \mathrm{l}$. The electrolyte containing sodium fluoride $(5 \mathrm{~g} / \mathrm{l})$ and silicate $(15 \mathrm{~g} / \mathrm{l})$ was selected to treat samples using the PEO-method.

The process of coatings formation was carried out on a plasma electrolytic oxidation unit. The frequency of the polarizing pulses was $300 \mathrm{~Hz}$, the duty cycle was $50 \%$. All samples were processed in two-stage bipolar PEO mode. At the first stage, the anodic component was fixed galvanostatically at a current density of $0.35 \mathrm{~A} / \mathrm{cm} 2$, and the cathodic one was fixed potentiostatically at $-30 \mathrm{~V}$. The duration of the first stage of PEO was $200 \mathrm{~s}$, while the anode voltage increased to $270 \mathrm{~V}$. During the second stage (duration of $600 \mathrm{~s}$ ) the anodic component changed potentiodynamically from the current value of voltage to $200 \mathrm{~V}$, and the cathodic one changed from $-30 \mathrm{~V}$ to $-10 \mathrm{~V}$.

The electrochemical tests were carried out using VersaSTAT MC (Princeton Applied Research, USA). Electrochemical impedance spectroscopy and potentiodynamic polarization were performed at room temperature using three-electrode cell Model K0235 Flat Cell (PAR, USA). The samples were studied in 3 wt. $\% \mathrm{NaCl}$ solution. The counter electrode was a niobium mesh covered with platinum. The reference electrode was saturated calomel electrode (SCE). The area of contact of the sample with electrolyte was $1 \mathrm{~cm} 2$. Before electrochemical tests, the specimens were immersed in the solution for $60 \mathrm{~min}$ to stabilize the electrode potential. The scan rate for potentiodynamic polarization was $1 \mathrm{mV} / \mathrm{s}$. The samples were polarized from $\mathrm{EC}-0.15 \mathrm{~V}$ up to $\mathrm{EC}+0.50 \mathrm{~V}$.

Studies of mechanical properties, in particular, determination of microhardness of the coatings were carried out using a DUH-W201 dynamic ultramicrohardness tester (Shimadzu, Japan). Measurements of the universal microhardness were carried out on a cross-section using a Vickers indenter at a load of $50 \mathrm{mN}$. The adhesive properties of the surface layers were investigated by scratch testing using Revetest Scratch Tester (CSM Instruments, Switzerland). The experiments were performed at a track length of $5 \mathrm{~mm}$ and a gradual increase in load from 1 to $20 \mathrm{~N}$ with a loading rate of $10 \mathrm{~N} / \mathrm{min}$. Rockwell diamond indenter was used for scratch testing.

\section{Results}

Influence of the electrolyte composition on the mode of plasma electrolytic oxidation is presented as a dependence of the current density and voltage on the PEO process time (Fig. 1).

Addition of silicon carbide nanoparticles interferes with anode reactions and delays sparking. Adding $2 \mathrm{~g} / \mathrm{l}$ of $\mathrm{SiC}$ nanopowder reduces the final anode voltage at the initial process stage down to $\sim 260 \mathrm{~V}$ (Fig. 1a). Subsequent increase in $\mathrm{SiC}$ concentration to $6 \mathrm{~g} / \mathrm{l}$ results in a consistent decrease in voltage till $\sim 230 \mathrm{~V}$ (Fig. 2a) for this electrolyte composition. Addition of nanoparticles into the electrolyte also led to an increase of the max value of cathodic current (Fig. 2b). This behavior can be explained by an increase in the 
heterogeneity of the coating, which leads to an increase in conductivity and, as a consequence, to an increase in the current density.
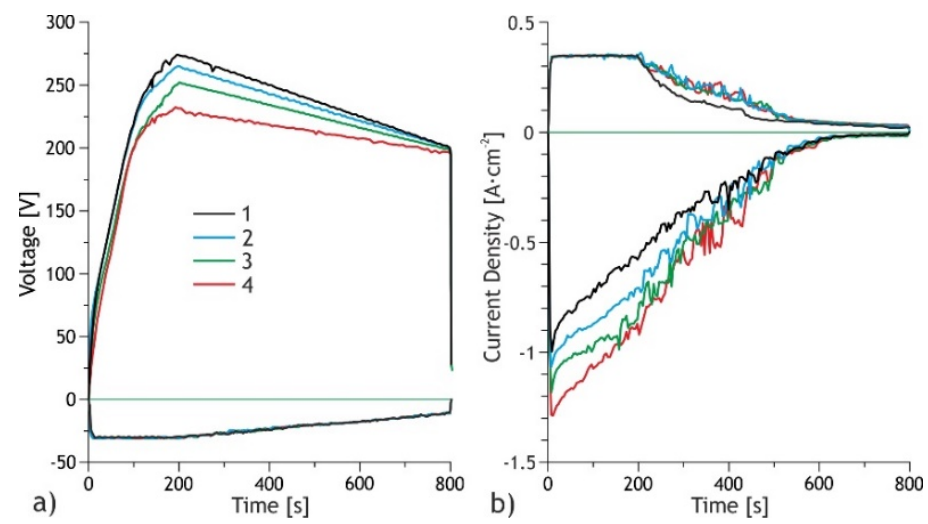

Fig. 1. Evolution of the (a) voltage and (b) current density with time of the PEO process for samples in different electrolytes: (1) without nanoparticles and with $\mathrm{SiC}$ nanoparticles concentration of (2) 2, (3) 4 , (4) $6 \mathrm{~g} / \mathrm{l}$.

Fig. 1 shows the appearance of the scratch, made to identify the mechanism of coatings destruction during the scratch test. An increase in the concentration of nanoparticles to $4 \mathrm{~g} / 1$ led to a slight change in the load $\left(\mathrm{L}_{\mathrm{C} 2}\right)$, at which the beginning of peeling of coating areas was observed, while an increase in load, at which abrasion of the coating to the substrate occurs $\left(\mathrm{L}_{\mathrm{C} 3}\right)$, was observed too (Table 1). The increase in the value of the parameter $\mathrm{L}_{\mathrm{C} 3}$ is due to an increase in the thickness of the coatings formed in electrolytes with $\mathrm{SiC}$ nanoparticles in comparison with the PEO-coating obtained in base electrolyte. The increase in the concentration of nanoparticles in the electrolyte up to $6 \mathrm{~g} / \mathrm{l}$ led to a decrease in adhesion strength, as evidenced by a decrease in $\mathrm{L}_{\mathrm{C} 2}$ parameter.

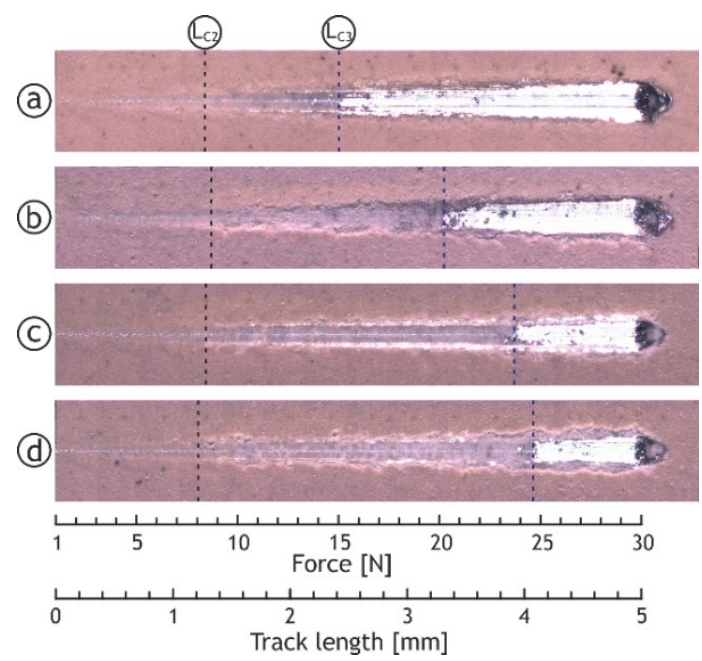

Fig. 2. Appearance of scratches on coatings obtained on MA8 magnesium alloy in silicate-fluoride electrolyte (a) without nanoparticles and with $\mathrm{SiC}$ nanoparticles in various concentrations (g/l): (b) 2 , (c) 4 , (d) 6 
Analysis of the results obtained by microhardness test (Table 1) revealed that nanoparticle-containing layers reveal the values of microhardness $(\mathrm{H} \mu)$ up to $3.7 \pm 0.2 \mathrm{GPa}$, which is higher than that obtained for the coatings formed in the base electrolyte $(\mathrm{H} \mu=(2.3 \pm 0.2) \mathrm{GPa})$.

The increase in the hardness of the coatings is associated with the incorporation of silicon carbide nanoparticles into their composition, which have a high hardness compared with the compounds forming the base PEO layer (orthosilicate, fluoride, and magnesium oxide).

Table 1. Mechanical properties of the studied coatings.

\begin{tabular}{|c|c|c|c|}
\hline Particle concentration $[\mathrm{g} / \mathrm{l}]$ & $L_{\mathrm{C} 2}[\mathrm{~N}]$ & $L_{\mathrm{C} 3}[\mathrm{H}]$ & $H_{\mu}[\mathrm{GPa}]$ \\
\hline 0 & $8.2 \pm 0.3$ & $15.1 \pm 1.3$ & $2.3 \pm 0.2$ \\
\hline 2 & $8.4 \pm 0.5$ & $20.3 \pm 1.5$ & $2.5 \pm 0.3$ \\
\hline 4 & $8.3 \pm 0.4$ & $23.7 \pm 1.7$ & $2.9 \pm 0.4$ \\
\hline 6 & $8.0 \pm 0.5$ & $24.6 \pm 1.6$ & $3.7 \pm 0.2$ \\
\hline
\end{tabular}
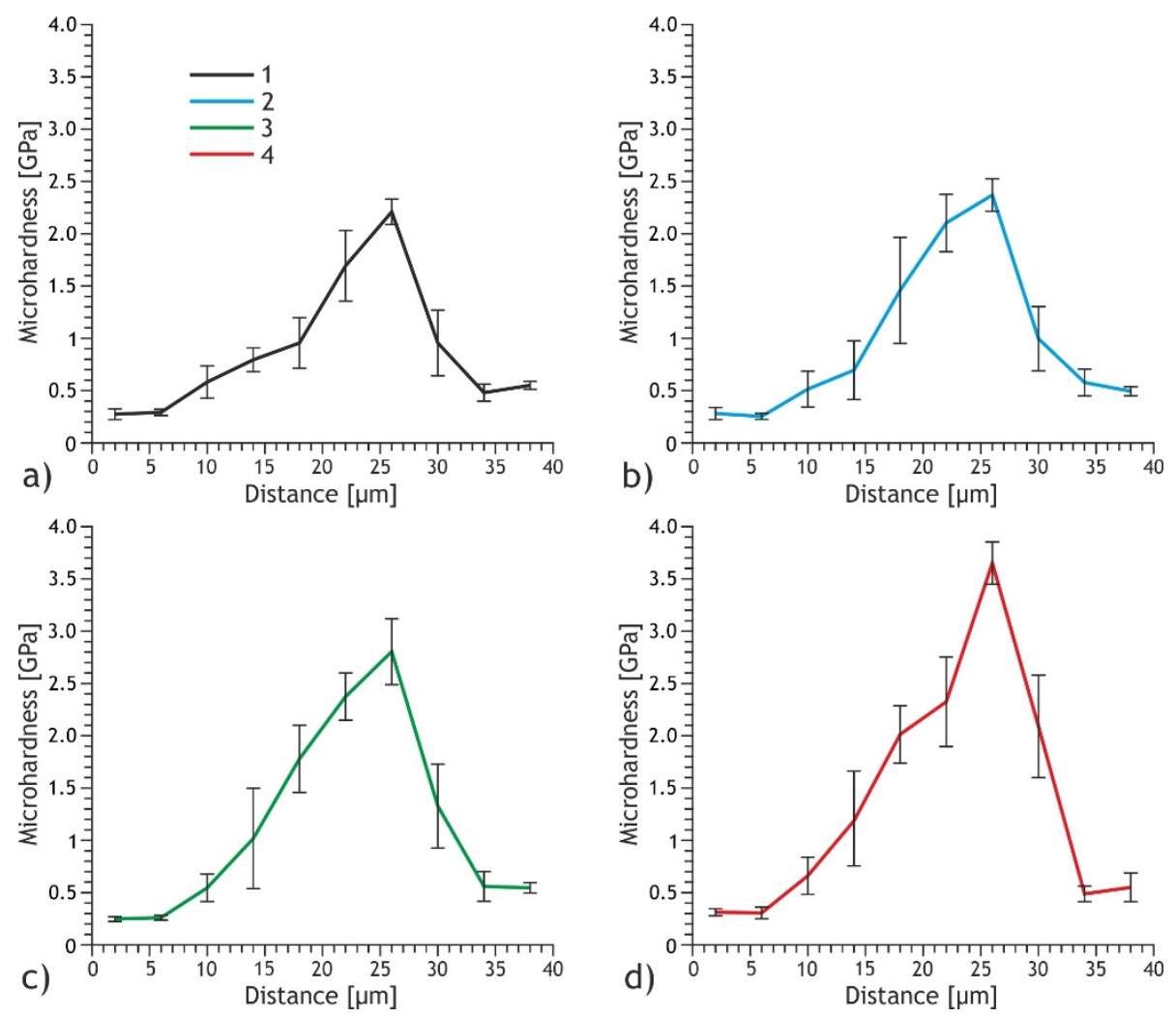

Fig. 3. Microhardness of coatings obtained on MA8 magnesium alloy in silicate-fluoride electrolyte (a) without nanoparticles and with $\mathrm{SiC}$ nanoparticles in various concentrations (g/l): (b) 2, (c) 4, (d) 6 


\section{Conclusions}

It has been established that PEO-coatings formed on the MA8 magnesium alloy in electrolytes containing $\mathrm{SiC}$ nanoparticles have improved mechanical characteristics in comparison with the surface layers obtained without the use of nanoparticles. The incorporation of nanoparticles led to an increase in the microhardness of the surface layers and the load at which abrasion of the coating to the substrate occurs by 1.6 times. Formed coatings are perspective for industry and can be used in aviation, automotive and biomedicine as protective layers.

The studies were carried out with the support of the Russian Science Foundation (project No. 20-1300130).

\section{References}

1. M. Kamil, M. Kaseem, Y. Lee, Y. Ko, J. Alloys Compd. 707, 167-171 (2017)

2. M. Aliofkhazraei, A. Rouhaghdam, Appl. Surf. Sci. 258, 2093-2097 (2012)

3. A. Gnedenkov, S. Lamaka, S. Sinebryukhov, D. Mashtalyar, V. Egorkin, I. Imshinetskiy, M. Zheludkevich, S. Gnedenkov, Corros. Sci. 182, 109254 (2021)

4. M. Mohedano, C. Blawert, M. Zheludkevich, Surf. Coat. Technol. 269, 145-154 (2015)

5. H. Nasiri Vatan, R. Ebrahimi-kahrizsangi, M. Kasiri-asgarani, J. Alloys Compd. 683, 241-255 (2016)

6. Y. Cheng, Q. Zhang, Z. Zhu, W. Tu, Y. Cheng, P. Skeldon, Ceram. Int. 46, 13385-13396 (2020)

7. S. Adsul, U. Bagale, S. Sonawane, R. Subasri, J. Magnes. Alloy. 9(1), 202-215 (2021).

8. D. Mashtalyar, K. Nadaraia, I. Imshinetskiy, E. Belov, V. Filonina, S. Suchkov, S. Sinebryukhov, S. Gnedenkov, Appl. Surf. Sci. 536, 147976 (2021)

9. Y. Lu, Y. Wang, H. Shen, Z. Pan, Z. Huang, L. Wu, Mater. Sci. Eng. A. 590, 368-373 (2014)

10. S. Wang, N. Si, Y. Xia, L. Liu, Trans. Nonferrous Met. Soc. China. 25, 1926-1934 (2015) 